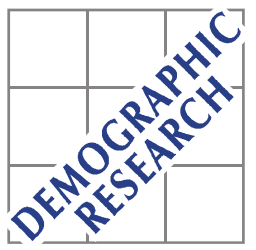

Demographic Research a free, expedited, online journal

of peer-reviewed research and commentary in the population sciences published by the Max Planck Institute for Demographic Research

Konrad-Zuse Str. 1, D-18057 Rostock · GERMANY

www.demographic-research.org

DEMOGRAPHIC RESEARCH

VOLUME 16, ARTICLE 16, PAGES 493-518

PUBLISHED 22 JUNE 2007

http://www.demographic-research.org/Volumes/Vol16/16/

DOI: 10.4054/DemRes.2007.16.16

Reflexion

\title{
Disciplining anthropological demography
}

\author{
Ernestina E. Coast
}

Katherine R. Hampshire

Sara C. Randall

(C) 2007 Coast, Hampshire \& Randall

This open-access work is published under the terms of the Creative Commons Attribution NonCommercial License 2.0 Germany, which permits use, reproduction \& distribution in any medium for non-commercial purposes, provided the original author(s) and source are given credit.

See http:// creativecommons.org/licenses/by-nc/2.0/de/ 


\section{Table of Contents}

$\begin{array}{lll}1 & \text { Introduction } & 494\end{array}$

2 Disciplinarity 494

2.1 Bridging disciplines: The rise of inter-disciplinary research 494

$2.2 \quad$ Practical barriers to inter-disciplinarity 497

2.3 Different forms of interdisciplinarity 499

$3 \quad$ Anthropological demography and disciplinarity 502

$3.1 \quad$ What is demography? 502

3.2 Who are demography's disciplinary links with? 503

$\begin{array}{lll}3.3 & \text { Demography \& anthropology } & 504\end{array}$

4 Discussion $\quad 509$

5 Acknowledgements 510

$\begin{array}{ll}\text { References } & 511\end{array}$ 


\title{
Disciplining anthropological demography
}

\author{
Ernestina E. Coast ${ }^{1}$ \\ Katherine R. Hampshire ${ }^{2}$ \\ Sara C. Randall ${ }^{3}$
}

\begin{abstract}
This study furthers the epistemological development of anthropological demography, and its role in understanding the demography of Europe. We sketch out broad issues to stimulate new productive interactions and understanding in order to initiate discussion around the overall research agendas of European anthropological demography. We situate anthropological demography against the context of an evolving world of research in which boundaries between academic disciplines have become much more permeable. This is achieved via an overview of recent theoretical debates about the role and nature of disciplinarity, including interdisciplinarity, multidisciplinarity and transdisciplinarity. In order to understand the current state of the art, we sketch out the evolution of anthropological demography, paying particular attention to the different knowledge claims of anthropology and demography. We conclude by summarising the potential disciplinary benefits of interdisciplinarity between anthropology and demography.
\end{abstract}

${ }^{1}$ Dept of Social Policy, London School of Economics. E-mail: E.Coast@1se.ac.uk

${ }^{2}$ Anthropology Department, Durham University. E-mail: k.r.hampshire@durham.ac.uk

${ }^{3}$ Anthropology Department, University College London. E-mail: S.Randall@ucl.ac.uk 


\section{Introduction}

In this chapter we will sketch out broad issues to stimulate new productive interactions and understanding in order to initiate discussion around the overall research agendas of European anthropological demography. Ultimately this chapter aims to further the epistemological development of anthropological demography, and its role in understanding the demography of Europe. We situate anthropological demography against the context of an evolving world of research in which boundaries between academic disciplines have become much more permeable. This is achieved via an overview of recent theoretical debates about the role and nature of disciplinarity, including interdisciplinarity, multidisciplinarity and transdisciplinarity. In order to understand the current state of the art, we sketch out the evolution of anthropological demography, paying particular attention to the different knowledge claims of anthropology and demography. ${ }^{4} \mathrm{We}$ conclude by summarising the potential disciplinary benefits of interdisciplinarity between anthropology and demography.

\section{Disciplinarity}

\subsection{Bridging disciplines: The rise of inter-disciplinary research}

Anthropological demography needs to be situated against the context of an evolving world of research in which boundaries between academic disciplines have become much more permeable, in both social science (e.g. gender studies) and physical science, and multi- and interdisciplinary research have become more common, although not necessarily more accepted or any easier to do well. The reasons for this increasing mixing of epistemology and method are manifold, and include globalisation (leading to easier and more frequent transfers of information and researchers), technological developments, and postmodernity (Riley \& McCarthy 2003). We must also acknowledge the critical role of research funding in both reacting to and shaping this evolution. International organisations, governments and funding agencies often emphasise inter- or multidisciplinary approaches in tackling research agendas, a

\footnotetext{
${ }^{4}$ A potential tension arises between social anthropology and biological anthropology with both subdisciplines having overlapping interests with demography. Several evolutionary anthropologists have recently published in demographic journals and had sessions in demographic conferences (for example, Interational Union for the Scientific Study of Population, XXV International Population Conference, 18-23 July 2005, Tours, France), and there is increasing interest in the relationships between demography and the biological/physical sciences (Boerma, 2001; Frank, 2001; Roth, 2004). However in this paper when speaking of anthropology and anthropological demography our reference is to social anthropology.
} 
position based on an understanding that it is at the boundaries and intersections of different disciplines that productive research agendas can be set and addressed. ${ }^{5}$ The culture of disciplines means that we must recognise that disciplinary knowledge is, of itself, a social product created and shaped by its disciplinary home. Here, a discipline is defined as "any comparatively self-contained and isolated domain of human experience which possess its own community of experts, with distinctive components such as shared goals, concepts, facts, tacit skills and methodologies" (Braun \& Schubert, 2003:183). Disciplines differ in the way in which they organise, produce and assess new knowledge - epistemology is a way of knowing, and each discipline has distinctive tools, concepts, methods and language. Disciplines have epistemological commitments (Schoenberger, 2001:367) which manifest through disciplinary culture, an academic social order that reproduces itself and goes beyond mere adherence to disciplinary tools, concepts, methods and language. Thus, institutions and practices contribute to sense(s) of disciplines and their reproduction and disciplines have different theories of knowledge, which guide research practice both implicitly and explicitly. The way in which scholarly endeavour has evolved into specialisms has been described as a "convenient demarcation of a field of knowledge that often has no reality in nature" (Fry, 2001:160).

We have to begin with an understanding of the concept of discipline. Whilst individual disciplines can be identified, any such undertaking involves "some degree of conceptual and historical arbitrariness" with one of the problems being that disciplines tend to become synonymous with academic departments. Aram notes "recognising ambiguities in the concept of discipline foreshadows the challenge of defining interdisciplinarity" (2004:381).

Terms such as multidisciplinarity, interdisciplinarity, transdisciplinarity, crossdisciplinarity and pluridisciplinarity are increasingly frequently used in the literature, to describe epistemologies, research teams, approaches, methodologies, and training. The absence of standard nomenclature and typologies makes it necessary to try to unpick the key themes and recent developments. Our position here is not to elevate multidisciplinarity above monodisciplinarity, because "interesting things also happen right at the core of individual research disciplines" (Gannon, 2005). This review does not undermine good research from one individual discipline, and does not presuppose

\footnotetext{
${ }^{5}$ See examples:

Global Science Panel on Population in Sustainable Development - which calls for more interdisciplinary research and education (2002) (http://www.iiasa.ac.at/Admin/INF/hague/)

Nantional Institute for Health's (NIH) Interdisciplinarity Roadmap for Interdisciplinarity Research Initiatives http://nihroadmap.nih.gov/interdisciplinary/

National Academies 'Keck Futures Initiative' To Transform Interdisciplinary Research http://www.wmkeck.org/contentManagement/PR_3f03bb3c-84d6-4516-b67a-d9b9af47d0e9.htm EU Framework Programmes (www.cordis.lu)

ESRC (www.esrc.ac.uk)
} 
that interdisciplinarity replace discipline-based research. The tensions between disciplinarity and interdisciplinarity are succinctly summarised by Harriss "discipline is productive...it produces the conditions for cumulation of knowledge...discipline is constraining and [that] it may be pushed to the point where it limits thought and so becomes constraining and even repressive rather than productive" (2002:487).

Interdisciplinarity is the "emergence of insight and understanding of a problem domain through the integration or derivation of different concepts, methods and epistemologies from different disciplines in a novel way" (Rogers et al, 2005). The emergence of interdisciplinarity is frequently in response to the belief that traditional disciplines are unable (or possibly unwilling) to address a particular research agenda, especially new and emerging research agendas. Thus interdisciplinarity is not an end in, and of, itself, but is a means to producing knowledge to address knowledge gaps that are inaccessible by monodisciplinarity. The potential outcomes and benefits of an interdisciplinary approach remain under debate. Aram questions whether interdisciplinary knowledge is any different to other types of knowledge, whereas Braun \& Schubert (2003) argue that interdisciplinarity produces new knowledge that would not be otherwise possible. It is worth noting that many researchers do not necessarily discuss or consider interdisciplinarity per se, rather collaboration is established when researchers find themselves working on issues that span disciplinary boundaries. Interdisciplinarity is an issue for virtually every discipline, and a wide range of literature discusses how individual disciplines deal with this development (for example: Law and political science - Bank \& Lehmkul; 2000; development - Harriss, 2002; gender - Jackson, 2002).

The definitions of interdisciplinarity are many and varied, and the study of interdisciplinarity has become an academic endeavour in its own right (Acutt et al, 2000; Aram, 2004; Paxton, 1996; Kockelmans, 1979; Stember, 1991; Finkenthal, 2001; Lattuca, 2001, 2002; Braun \& Schubert, 2003; Weingart \& Stehr, 1999; Metzger \& Zare, 1999; Heberlein, 1988; Heintz \& Origgi, 2003; Klein, 1990; Klein \& Newell, 1998; Lattuca, Voigt \& Fath, 2004; Frickel, 2004; Marzano, Carss \& Bell, 2006). To give a flavour of the emerging definitions of interdisciplinarity, three "working definitions" are given here:

Acutt et al 2000:4

"an eclectic approach integrating different disciplines for solving complex problems encompassing methodologies, methods and worldviews. It involves an interactive, communicative, information-based and holistic way of thinking. It is fluid and adaptable to the problem that has to be solved" 
Klein \& Newell (1998:3) - quoted in Aram (2004:382)

"a process of answering a question, solving a problem or addressing a topic too broad or complex to be dealt with adequately by a single discipline or profession...draws on disciplinary perspectives and integrates their insights through construction of a more comprehensive perspective"

Strathern (2005: fn17)

interdisciplinarity work is defined as purposeful means to a cognitive or practical goals... with the stipulation that the "disciplinary lenses be integrated in mutually informative networks of relationships rather than simply juxtaposed" quoting Mansilla \& Gardner, 2003:2)

What emerges then is that even relatively straightforward definitions suggest a sense of common understanding of what disciplines are, who does them, and what they represent. The review below is necessarily selective of the large and rapidly growing literature on the subject of interdisciplinarity. Interdisciplinarity emerged post-1950 in western academic institutions (Klein, 1996) in response to rapidly changing "knowledge landscape" (Miller \& Mansilla, 2004) typified by greater and speedier knowledge production and exchange alongside a shift in the kinds of issues addressed by academics.

\subsection{Practical barriers to inter-disciplinarity}

In practice, the issues is how to inter-relate conceptual insights and knowledge from different disciplines that can often be mutually antagonistic. There are many practical barriers to interdisciplinarity, including ${ }^{6}$ :

\section{Training:}

Most researchers are trained in individual disciplines therefore any interdisciplinary project must factor in time, funding and effort to ensure that researchers both understand and recognise the value of other approaches. ${ }^{7}$

\footnotetext{
${ }^{6}$ See Caruso \& Rhoten (2001), Fry (2001) and Heintz \& Origgi (2003) for detailed reviews of practical barriers to interdisciplinarity

${ }^{7}$ Vis à vis anthropological demography, the Population Studies and Training Centre at Brown University is one of the few places to offer explicitly interdisciplinary training (http://www.pstc.brown.edu/)
} 


\section{Funding:}

Research funding calls for interdisciplinary agenda are often peer-reviewed by individuals drawn from traditional disciplines. Sperber (2003) refers to "cosmetic interdisciplinarity" required by research grants committees which tend to favour grant proposals that build in interdisciplinarity rhetoric without necessarily delivering interdisciplinarity. Fry (2001) notes that the practical problems of interdisciplinarity are often overlooked by management and funding agencies.

\section{Recognition/ Assessment (publication):}

Peer-reviewed publication is the benchmarked outcome of most research programmes, raising issues of publication outlets for such research (again here the issue of monodiscipline peer-reviewers raises its head). But what happens if peers do not exist for the interdisciplinarity research in hand? Jackson refers to this as the "political economy of academic research", and Strathern notes that "measures that directly address epistemic dominions of interdisciplinarity works...[are]....rarer and less well articulated" (2005:83).

\section{Institutional structures:}

These can work to reduce the incentives for interdisciplinary work, not least because individual disciplines tend to be reflected in academic structures (faculties, schools, etc.)

\section{Time and effort}

Interdisciplinary projects need time to acquire training, incorporate perspectives and develop research strategies, time which is rarely included in the budget lines of grant proposals. Heintz \& Origgi refer to this as "cognitive constraints" (2003), whereas Nowotny (2003) simply calls it "patience".

\section{Willingness (and ability) to do it}

Jackson (2002) refers to the "social costs to researchers" and Schoenberger highlights the inherent risks because of the peer review process making interdisciplinarity very difficult for more junior academics. Furthermore, the increasingly rapid production of new knowledge can make the ideals of interdisciplinarity a burden, even if the researcher is willing and able to learn a new disciplinary "language". Mansilla et al argue that successful interdisciplinarity requires researchers to embody "a disposition towards curiosity, risk-taking, open-mindedness and humility" (2000).

As with any academic endeavour, interdisciplinarity can be done well or it can be done badly (see Fry, 2001 for characteristics of good interdisciplinarity). There is 
growing concern about the primacy (within and beyond academia) given to interdisciplinarity and Jackson cautions that interdisciplinarity runs the risk of the "lowest common denominator effect" (2002:499), whereby the difficulties of doing interdisciplinarity work mean that only the simplest of research questions are posed. McGregor suggests that true interdisciplinarity is more difficult to realise than the "flippant" way it is used by funding agencies and researchers alike (2004). Within the literature produced by interdisciplinary projects it is rare that one sees clear pathways from the interdisciplinarity referred to in the grant application to the outcomes. For example, the Centre for Economic Learning and Social Evolution, based at University College London, notes that in their work interdisciplinarity "has most of the time taken the form of an exchange of ideas among several disciplines...rather than the form of explicit interdisciplinarity work" (2002:13). This is an example of what Strathern refers to as "intangible information-sharing....the most central and creative aspect of the interdisciplinarity research collectivity... one of the most under-appreciated and unrewarded activities" (2005). Greenhalgh's (2001) review of Entwistle \& Henderson's work on China notes that the research was "originally envisioned as a vehicle for the interdisciplinary creation of a synthetic model...this was a tall order, indeed, so tall that the editors...eventually abandoned it". Strathern cautions, "There is nothing straightforward about bringing together organisations with different aims and objectives and diverse cultures - there is nothing straightforward about bring together disciplines, either" (2005:82). Interdisciplinary endeavours, by their very nature, will evolve over time.

\subsection{Different forms of interdisciplinarity}

Study of the nature of interdisciplinarity has yielded a range of research attempting to typify different "types" of interdisciplinarity, all of which have in common a continuum from less to more disciplinary integration (for example: Fry, 2001; Acutt et al, 2000; Klein, 1996; Lattuca, 2001; Paxton, 1996; Mansilla, Dillon \& Middlebrooks, 2000). To illustrate the different forms of interdisciplinarity we use a series of diagrams with common schema: Thick black lines represent individual disciplines (discipline A, discipline $\mathrm{B}$, etc.) and dashed lines represent disciplinary epistemology, data and methods.

Multidisciplinarity ${ }^{8}$ may be typified as a cooperation between disciplines that neither readily integrates the findings of different disciplines nor adequately addresses knowledge gaps (Acutt et al, 2000:7) (Figure 1). Braun \& Schubert succinctly define it as "when disciplines work side by side on distinct problems or aspects of a single

\footnotetext{
${ }^{8}$ Also referred to as pluridisciplinarity by Acutt et al 2000 .
} 
problem" (2003:183). Thus, one of the most common ways in which interdisciplinarity is tackled pragmatically is via multidisciplinarity, a form of interdisciplinarity whereby researchers from different disciplines work collaboratively but without altering their individual disciplinary epistemologies or methodologies or theories. That is, they work in parallel, which can result in final project reports that are little more than a series of seemingly unconnected results on the same issue, bound together by introductory and concluding paragraphs. Indeed, Gannon suggests that many projects find themselves developing reactively to the need for interdisciplinarity from funding agencies by including a cooperative collaborator with little evidence for research quality improvement, a sentiment echoed by Miller (1997). Multidisciplinarity is frequently taken for granted in collaborative research projects, although rarely addressed systematically. If multidisciplinary studies are designed well with a clear focus they can provide useful insights, but are generally not considered as productive or powerful as interdisciplinary research.

Transdisciplinarity ${ }^{9}$ has been described as the most controversial form of interdisciplinarity (Heintz \& Origgi, 2003), representing a very high degree of integration where theories, models and methods merge. True transdisciplinarity is probably the most difficult form of interdisciplinarity to achieve in practice, since it involves all researchers having a comprehensive understanding of, and being equally comfortable with, working within two or more disciplinary paradigms.

${ }^{9}$ Haberli et al (2001) "a new form of learning and problem solving involving cooperation among different parts of society and acadaemia in order to meet complex challenges of society". 
Figure 1: Multidisciplinarity

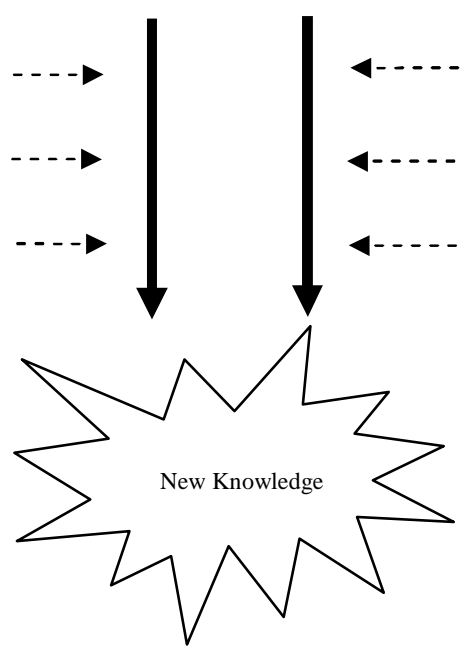

Figure 2: $\quad$ Transdisciplinarity

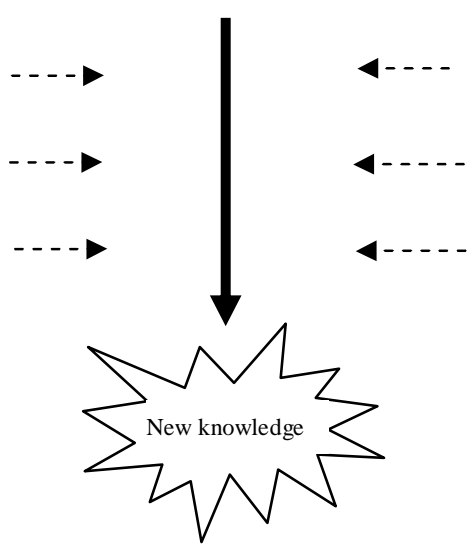


Between these two lies a range of practices, which involve more genuine communication between disciplines than can be achieved in merely multi-disciplinary research projects, while not requiring all of the very high investments in time and training that would be required for truly transdisciplinary research. In this "third way" (Figure 3), each discipline informs the other(s) at all stages of the research project, but it is not expected that each researcher will be an expert in all disciplines. Such a model might involve a team of researchers, each of whom are specialists in one discipline, but conversant with the other(s), plus sufficient resourcing to allow frequent and meaningful communication between the different disciplinary researchers at all stages in a research project.

Figure 3: Third way: each discipline informing the other throughout research process

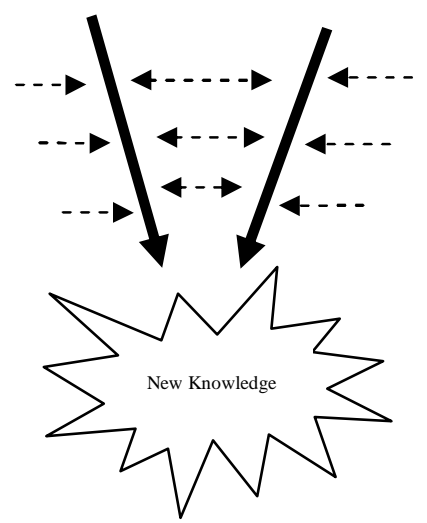

\section{Anthropological demography and disciplinarity}

\subsection{What is demography?}

According to the multi-lingual demographic dictionary demography is the 'Scientific study of human populations, primarily with respect to their size, their structure and their development' (POPIN, 1993). Garrett Hardin in 1991 put it more succinctly: 'Demographers - the specialists officially in charge of population studies - are neither optimists or pessimists. They see their task as one of counting everything human' (p.339). But the reality of demography today is moving away from this accountancy or 
bank clerk approach, although it is a characteristic frequently referred to in the demographic literature (Greene \& Biddlecom, 2000; Lesthaeghe, 1998). This accounting approach spent much time dealing with bias in data and refining methods for 'correcting' data to render them closer to what was thought to be the reality (often represented by mathematical formulae). The definition of demography varies widely, but tends to be broad and emphasise interrelationships with other disciplines (for example, Stycos, 1987; Liu \& Wang, 2005; Keyfitz, 1993; Riley \& McCarthy, 2003). Demography can be typified as a discipline that has strong ties to policy-making (not least the interrelationship with family planning), clear boundaries to its areas of study (namely: fertility, mortality and migration) $)^{10}$, has a strong empirical tradition, and most importantly is typified by a positivist epistemology. Demography has been singled out as a discipline that has been slow to react to critiques of the positivist approach that have been debated in other social sciences for considerably longer (Riley \& McCarthy, 2003). Within the discipline of demography today, there is less need to count and a much greater need to understand how and why demographic events happen, rather than how many and when.

\subsection{Who are demography's disciplinary links with?}

There has long been extensive cross-disciplinary work between demography and other disciplines, including but not exclusively: genetics (e.g.: Vetta \& Courgeau, 2003); evolutionary ecology and biology (Foster, 2003; Roth, 2004); political economy (Greenhalgh, 1990); feminism (Presser, 1997; Greenhalgh, 1995); and environment (e.g.: Pebley, 1998) amongst others. There has also been a longstanding crosspollination between demography and economics, from the time of Malthus.

One way in which inter-disciplinary relationships have been assessed and analysed is through citation analysis. Liu and Wang (2005) use this approach to "explore the intellectual structure of demography by revealing connections within its subject specialities and outside them" (p308). However a major shortcoming of using journals to look at relationships between disciplines is that it presupposes a disciplinary culture where journals are the pre-eminent dissemination medium. This is simply not the case for social anthropology where edited collections and monographs are the most prestigious output. This limits assessments of reviews of cross-disciplinary working using large-scale electronic archives such as IBSS and JSTOR.

\footnotetext{
${ }^{10}$ This may be contested. Judging by recent publications in the major demographic and population journals contemporary demography extends far wider into family formation, education, health, ageing, workforce, environment, etc.
} 


\subsection{Demography \& anthropology}

Anthropological demography is evolving out of a conjunction between two individual disciplines: demography and anthropology. Whether this endeavour is multidisciplinary or interdisciplinary (or indeed, some further form of collaboration) remains to be seen but to begin with it is necessary to sketch out the key aspects of each of these traditions. What follows here owes much to the excellent overviews by Greenhalgh (1995), Riley \& McCarthy (2003), Kertzer \& Fricke (1997) and Basu \& Aaby (1998), and does not seek to supplant them, nor to enter into the critiques of anthropology by demographers or those of demography by anthropologists. Rather, building upon the existing reviews, we shall focus on the ways in which demography and anthropology make claims about "their" knowledge. More demographers than anthropologists are concerned with the integration of the two disciplines, and this is reflected in the emphasis of the overview that follows.

Cross-disciplinary interest has clearly not been a two way street. There have been relatively few(er) anthropologists engaging with advances in demography, both in terms of theory and policy relevance ${ }^{11}$, also noted by Kertzer and Fricke (1997:2) and Caldwell (1996). The participants at the European Anthropological Demography workshop, of which this paper is a reflexion, underscore this direction of interest, with participants largely drawn from demography rather than anthropology. Demographers' developing interest in anthropology, or, perhaps in just what they perceive to be anthropology (Hammel 1990, Coast 2003) has included two decades of claims to draw on anthropological methods (the most prolific typified by the work of Caldwell \& Caldwell), although demographers have rarely used participant observation which might be claimed as the method that epitomises anthropology. Participant observation is incompatible with the demographic epistemology that gives primacy to representativeness and repeatability and which tends to be constrained by a need to get results quickly. The consequence is a burgeoning of qualitative demographic data which may ultimately be inspired by anthropology but can hardly be labelled anthropology (Randall \& Koppenhaver 2004). What most interests demographers, and yet simultaneously is most traumatic for them because it undermines the whole positivist, empirical platform on which demography is built, is the utility of qualitative data to investigate "problematic behaviours" that do not fit in with the philosophy of reasoned action, a notion that underlies much of the demographic enterprise (for example, survey questions on ideal family size). Qualitative data are also seen as a solution to researching 'sensitive' topics (such as abortion, teenage sexual activity, sexual practices) in which demographers are very interested but where responses to

\footnotetext{
${ }^{11}$ The critical importance of policy relevance to demography is perhaps one of the barriers to such engagements.
} 
formal questionnaires are unreliable for a variety of reasons. Although lip service is paid to anthropological methods ${ }^{12}$, the theoretical concepts that inform anthropology are rarely considered in demographic debates. Postmodern approaches in anthropology are interpretative, with an understanding that knowledge cannot be taken out of its context and be compared with knowledge from another context. Within anthropology itself there are debates and concerns about disciplinary evolution, and the knowledge it produces. Descola asks, "Is it rather the case that so many different enterprises have now clustered under the banner of anthropology that the huge extension acquired by this label condemns it to mean almost nothing, save the desire of those who employ it to signal that they favour a qualitative approach to social facts" (2005:65). Moore argues that there is no single anthropology, and that at its core anthropology resists abstract generalisations, the result of which is described as "an attachment to the particular" (Rapport, 2000:736).

Social anthropologists and demographers are inherently interested in the same topics and events, although the ways they are developed, understood and even the vocabulary used are very different. Thus, for anthropology these same events are perceived to be culturally specific; they cannot be understood outside of the context in which they appear and independently of the meanings that people attribute to them. The same events might have different meanings and implications in different settings and from different perspectives. All events are a product of the interaction between structure and agency, that is, the extent to which social actors shape events rather than the extent to which they are shaped by social, economic and political conditions. Thus, the anthropological focus on processes implicitly acknowledges that "factors" are not independent of subjective meanings given them by actors. There are no "social facts" to be compared, rather there are social phenomena resulting from actors' construction and interpretations of them. By contrast, in demography, events of the same type are treated as essentially interchangeable. One birth or one death is much the same as any other save for specific characteristics by age or sex, and analysis hinges around whether such events are more or less likely to happen, and risk factors. ${ }^{13}$

There is a tension between the aggregate and the individual, and how they are approached in the two disciplines. Until very recently, demography was generally taught with an emphasis on the aggregate where 'individual-level' analysis means using individual level data to research the aggregate. In general, demographers tend to exclude exceptions seeing them as unrepresentative "outliers" or a function of error at some stage of data production. Such outliers are generally seen to fall outside the

\footnotetext{
${ }^{12}$ Although 'qualitative methods' is probably a better description.

${ }^{13}$ Demographers have occasionally explored the consequences of some births being more sought after or favoured than others especially when focusing on the interplay of sex and birth order in south Asia (Muhuri \& Preston, 1991, Das Gupta, 1987). Such work often arises out of hypotheses thrown up by ethnographic accounts.
} 
boundaries which determine appropriate areas of intellectual (and practical) interest. In contrast an anthropologist is more likely to use exceptions to understand the rules and the boundaries and their dynamics. Anthropology is critical of the superimposition of anthropological knowledge onto contexts larger than that in which the knowledge was generated. Anthropological knowledge does not reject objective reality, rather, its explanatory power tends not to deal with large-scale phenomena because the implicit understanding is that these phenomena are driven by manifold processes rather than single "factors". Anthropologists and demographers have different kinds of knowledge, and different understandings of how their respective knowledge can be accessed. For anthropologists there is no fixed view of knowledge. Rather, it is subjective and (re)interpretable. Moreover, for anthropologists, there is an important dialectical relationship between power and knowledge (Foucault, Bourdieu). In other words, knowledge is not neutral and value-free, but is bound up with power relations, and the ability of some individuals and groups to define what constitutes legitimate ways of representing the world (Hampshire et al 2005).

Another tension is the role of comparison. Whilst indirect comparison is used frequently in anthropology as an orienting reference, for most contemporary anthropology comparison is simply not a valid or appropriate exercise, although there are anthropologists who do explicitly comparative work (e.g.: Jordan, 1992, Busby, 1997; Gregor \& Tuzin, 2001). For demography, comparison is such a fundamental tool that potential for comparison is implicitly built into almost all studies and many of the statistical methods depend on comparison (relative risk, odds ratios). In order to understand determinants of a demographic outcome demographers might compare coefficients between different subgroups having already controlled for known differences. Comparison is integral at all levels of the demographic enterprise. Many of the international survey series (WFS, DHS, FFS) essentially use the same questionnaire and concepts to facilitate comparisons -with $\mathrm{PhDs}$ emerging which compare Ghana with Senegal, different North African populations, West and East Africa, Asia and Africa etc - the possibilities are endless. Even within-country analyses of such data sets fundamentally aim to understand through comparison between ethnic groups, between education categories, between regions. It is hard to imagine a demographic journal without any comparative studies. Such a comparative perspective is not limited to demography but is a function of much of the more quantifiable social sciences. Anthropologists tend not to do much explicitly comparative research, not least because of concerns about "decontextualising human behaviour" (Georgiadis, 2007). Comparison is seen to be difficult, often verging on the impossible because inevitably too much differs: language, power systems, political context, history, sexuality, etc. 
For both disciplines there is an inherent interest in terms of dynamics of acquisition and loss of members to social groups. For demographers this is largely through accounting-type procedures (births in and deaths out) in contrast to the anthropological focus on how people become members of social groups, multiple ways of entering and leaving, the different levels of membership and how these can be negotiated. Anthropologists use analytic concepts such as kinship, identity and personhood to examine and understand the positions of birth and death whereas demographers use proximate determinants (Bongaarts \& Potter 1983, Mosley \& Chen 1984). To summarise, disciplines, the "building blocks" of multi- and interdisciplinarity, have such different ways of seeing the social world that at every stage of the research process we can identify contrasting stereotypes (Table 1).

A brief review of demographers and anthropologists using each other's knowledge sheds light on some of the tensions. Demographers tend to have a mechanistic and illinformed use of ethnographies (Coast 2003). Quotes are often poorly (or entirely un-) grounded when used by demographers (Randall, 2006). Anthropologists tend to present poor or inadequate use of quantitative data. ${ }^{14}$ Often anthropologists do not use data collected and analysed by demographers as their representation of a demographic context, and are more inclined to collect their own data thus using demographic data without the methods, theory or epistemology. Finally, when anthropologists represent demographic change it may be based on a few examples which stand out in their minds (probably because of the fact that they are different) rather than on population level data. They also tend to be unaware of biases, omissions etc (eg Keenan 2006, McKinnon 1997; Charsley, 2005)

\footnotetext{
${ }^{14}$ For example, Stenning (1995 [1959]) provides figures for marriage and divorce without referring to population age distributions.
} 


\section{Table1: $\quad$ Research method stereotypes}

\begin{tabular}{|c|c|c|}
\hline & Demography & Anthropology \\
\hline $\begin{array}{l}\text { Ask different } \\
\text { questions }\end{array}$ & $\begin{array}{l}\text { What are the determinants of....? } \\
\text { How strong is the influence of } x, y \text { and } z \text { on specific } \\
\text { outcomes? } \\
\text { In what ways does population } p \text { differ from population } q \text { ? } \\
\text { How can we quantify the determinants of these } \\
\text { differences? }\end{array}$ & $\begin{array}{l}\text { What is the social construction of....? } \\
\text { How can we understand....? } \\
\text { How does } x \text { work? } \\
\text { What is the (local) meaning of } x, y ? \\
\text { How do people perceive/ practice } x, y ? \\
\text { What can explain this perception/ practice? }\end{array}$ \\
\hline $\begin{array}{l}\text { Use different } \\
\text { methods and } \\
\text { sampling } \\
\text { strategies }\end{array}$ & $\begin{array}{l}\text { Surveys, direct questions, statistical analysis, sampling } \\
\text { frame, known probability of being included, random } \\
\text { samples, large samples }\end{array}$ & $\begin{array}{l}\text { Participant observation, interviews, } \\
\text { discourse and narrative analysis, media, life } \\
\text { histories, Key informants, snowball } \\
\text { sampling, small numbers of knowledgeable } \\
\text { respondents }\end{array}$ \\
\hline $\begin{array}{l}\text { Different } \\
\text { approaches to } \\
\text { and analysis of } \\
\text { data }\end{array}$ & $\begin{array}{l}\text { Quantitative data: everything expressed in closed } \\
\text { categories. Responses given accepted (largely) as } \\
\text { appropriate representations. Discard contradictions as } \\
\text { errors. Careful attention to definition to avoid ambiguity. } \\
\text { Concern with reliability, validity, objectivity and } \\
\text { repeatability. Assumption that there is an unproblematic } \\
\text { relationship between what people say and what they do. }\end{array}$ & $\begin{array}{l}\text { No one perspective or vocabulary preferred. } \\
\text { Analysis of social phenomena infused with } \\
\text { meaning. Accept that responses change } \\
\text { over time, over space and over specific } \\
\text { context. Explore contradictions and } \\
\text { ambiguity, rather than dismiss as errors. } \\
\text { Relationship between narrative and practice } \\
\text { less straightforward. } \\
\text { Knowledge is not value-free, but embedded } \\
\text { in power relations. }\end{array}$ \\
\hline $\begin{array}{l}\text { Situate } \\
\text { researcher } \\
\text { differently vis à } \\
\text { vis research } \\
\text { setting }\end{array}$ & $\begin{array}{l}\text { Researchers rarely involved in field data collection. } \\
\text { Those who collect data in field are lowest status, lowest } \\
\text { paid, least educated, least understanding of purpose of } \\
\text { data collection. } \\
\text { Questions piloted, translated and back translated } \\
\text { Data double entered and cleaned but little attention paid } \\
\text { to what actually happens at point of interview } \\
\text { Assumption that any sufficiently-trained researcher will } \\
\text { produce the same data outcomes }\end{array}$ & $\begin{array}{l}\text { Researchers usually collect data } \\
\text { themselves. } \\
\text { Learning language prioritised to understand } \\
\text { emic categories. } \\
\text { Highly sensitive to researcher-subject } \\
\text { interactions: power, gender, } \\
\text { insider/outsider. } \\
\text { Intimately concerned with researcher } \\
\text { reflexivity. }\end{array}$ \\
\hline $\begin{array}{l}\text { Communicate } \\
\text { research in } \\
\text { different ways }\end{array}$ & $\begin{array}{l}\text { Seminars / conferences - presentations, PowerPoint, } \\
\text { graphs, tables. } \\
\text { Language just a means of conveying an objective reality. } \\
\text { Publish in journals }\end{array}$ & $\begin{array}{l}\text { Seminars / conferences with verbatim } \\
\text { reading of papers, because more } \\
\text { concerned with language used to express } \\
\text { ideas } \\
\text { Publish in edited volumes / single authored } \\
\text { books/ monographs }\end{array}$ \\
\hline
\end{tabular}

${ }^{15}$ Given this, it is extraordinary how good the data are. Susan Watkins, based on work in Malawi, (pers. Comm.) has noted that, for qualitative research, if secondary school drop-outs are used as interviewers then data quality tends to be better than that collected by university graduates. This is because secondary school drop-outs are socially closer to the researched poorer rural women. 


\section{Discussion}

Anthropological demography is not demography that uses qualitative methods (aka qualitative demography). Epistemology and method are inter-related and inform each other. Mere transfer of methods tends to be problematic because without an understanding of the epistemology informing those methods, then their use can be counterproductive (Randall \& Koppenhaver 2004). The same methods used in different disciplines produce different knowledge with different meanings (Greenhalgh, 1997). What lessons, therefore, can demography learn from anthropology, and vice versa (Table 2)?

Table 2: What lessons can demography learn from anthropology, and vice versa?

\begin{tabular}{|c|c|}
\hline What can demography learn from anthropology? & What can anthropology learn from demography? \\
\hline $\begin{array}{l}\text { Questions and data collection are never entirely neutral or } \\
\text { objective. }\end{array}$ & $\begin{array}{l}\text { Population level phenomena may be different from } \\
\text { people's perceptions of them. }\end{array}$ \\
\hline There are multiple truths or realities. & $\begin{array}{l}\text { Demography can make anthropologists aware of issues, } \\
\text { trends and phenomena that they would otherwise be }\end{array}$ \\
\hline $\begin{array}{l}\text { Not all phenomena can be explained by theories of reasoned } \\
\text { action. }\end{array}$ & unaware of. \\
\hline $\begin{array}{l}\text { Some important influences on people's behaviour (e.g. gender } \\
\text { ideologies) cannot be quantified straightforwardly or objectively. }\end{array}$ & $\begin{array}{l}\text { Aggregate phenomena challenge anthropologists to } \\
\text { consider why some phenomena (e.g.: low fertility) occur } \\
\text { in such different contexts (e.g.: Japan and southern } \\
\text { Europe). }\end{array}$ \\
\hline $\begin{array}{l}\text { Power relations exert an important influence on people's actions } \\
\text { and on research and data collection processes. }\end{array}$ & $\begin{array}{l}\text { It is possible to learn new things from simplified } \\
\text { categories in survey data. }\end{array}$ \\
\hline $\begin{array}{l}\text { Questions and other forms of knowledge may be interpreted } \\
\text { differently by interviewers and interviewees. } \\
\text { Standardising methods is no guarantee of comparable answers. }\end{array}$ & $\begin{array}{l}\text { Quantifiable time trends may be important sources of } \\
\text { information about change that is imperceptible to } \\
\text { individuals }\end{array}$ \\
\hline $\begin{array}{l}\text { Individuals should not be considered as isolated and independent } \\
\text { but as socially embedded actors. }\end{array}$ & $\begin{array}{l}\text { Quantitative data may highlight associations which } \\
\text { otherwise would remain unexplored. }{ }^{16}\end{array}$ \\
\hline $\begin{array}{l}\text { Identity is complex, multiple and shifting, and cannot adequately } \\
\text { captured by simple categories such as "religion", "ethnicity", etc. }\end{array}$ & $\begin{array}{l}\text { Constraints may be caused by population dynamics over } \\
\text { which people have no control (e.g.: marriage squeeze) }\end{array}$ \\
\hline
\end{tabular}

Most anthropological demography to date has been concerned with the developing world, while the use of social theory and qualitative methods to understand

${ }^{16}$ See, for example, Kertzer \& Fricke "Perhaps the fuller engagement of demographic research in social theory will help convince anthropologists that there is a pay-off to being able to read the demographic literature, offering them an incentive to learn the necessary statistical method so that they can do so" (p.24) 
demographic processes in Europe has traditionally been the preserve of sociology (Gerson, 1985; Procter and Padfield, 1998, Bartlett, 1994 Rindfuss et al, 1988). Over the last couple of decades, anthropology as a discipline has been engaging increasingly with the "local". Indeed, processes of globalisation and cosmopolitanism, with increasing numbers of people and goods moving between geographical areas, mean that the "fields" in which anthropologists work become increasingly deterritorialised (e.g. Shaw 2000, Werbner 2002). Anthropological demography, on the other hand, has continued to focus almost exclusively on "the other" or "the exotic", partly, perhaps, because this is what demographers think that anthropologists do. This current volume represents an important new shift from seeing anthropological demography as being concerned primarily with the geographically distant "other" to being able to address issues much closer to home.

Anthropologists can teach demographers to be less positivistic and more open to the idea that their reading of data is partly determined by culture-centric assumptions, and that some of the terms used by demographers (for example, "outcomes" and "determinants") have very complex and diverse meanings cross-culturally. An important insight from postmodern anthropology is that the researcher can never be neutral bystander in relation to the research. Research findings are, to some extent, generated by the interaction between researcher and informant, rather than being "objective", or "out there". This sits uncomfortably beside the gold standards of validity and reliability expected of conventional demographic research. This point highlights the inherent link between theory, epistemology and data analysis. Most studies that use qualitative methods to investigate demographic phenomena (qualitative demography) tend to interpret interview data almost exclusively within a "realist" tradition, in which informants' words are seen as offering a window into human experience (Ryan and Bernard, 2000). It is our contention, however, that it is vital to continue to consider critically our disciplinary culture(s), regardless of whether research involves one or more disciplines. It is only through such reflexivity that what JohnsonHanks refers to as "multidisciplinary effervescence" can be achieved (2003:736).

\section{Acknowledgements}

This paper was developed out of a plenary discussion at the "First Workshop of the Anthropological Demography of Europe: state of the art and perspectives", 30th September-1st October 2005, Max Planck Institute for Demographic Research. We are grateful for the comments of two anonymous reviewers. 


\section{References}

Acutt, N., A. Ali, E. Boyd, A. Hartmann, J. A. Kim, I. Lorenzoni, I., M. Martell, A. Pyhala, \& A. Winkels. (2000). "An interdisciplinary framework for research on global environmental issues." CSERGE Working Paper (The Centre for Social and Economic Research on the Global Environment) 2000-23.

Aram, J. D. (2004). "Concepts of interdisciplinarity: configurations of knowledge and action." Human Relations 57(4): 379-412.

Bank, R. and D. Lehmkuhl (2000). "Law and politics and migration research." MPI Collective Goods Preprint 15.

Bartlett J. (1994). Will you be mother? Women who choose to say no. London: Virago Press.

Basu, A. M. and P. Aaby (1998). Methods and uses of anthropological demography. New York, Clarendon Press.

Boerma, J. T. (2001). "Review of "Cells and surveys: should biological measures be included in social science research?" Finch, C. E., J. W.Vaupel, \& K. Kinsella (Eds.)." Population and Development Review 27(3): 605-607.

Bongaarts, J. \& R. G. Potter (1983) Fertility, Biology, and Behavior: An Analysis of the Proximate Determinants in Braun, T. and A. Schubert (2003). "A quantitative view on the coming of age of interdisciplinarity in the sciences 1980-1999." Scientometrics 58(1): 183-189.

Busby, C. "Permeable and Partible Persons: A Comparative Analysis of Gender and Body in South India and Melanesia" Journal of the Royal Anthropological Institute (NS) 3, 261-278

Caldwell, J. C. (1996) Demography and social science. Population Studies, 50(3):305333

Caruso, D. and D. Rhoten (2001). Lead, follow, get out of the way: sidestepping the barriers to effective practice of multidisciplinarity. A new mechanism for knowledge production and re-integration in the age of information. A Hybrid Vigor White Paper, The Hybrid Vigor Institute.

Centre for Economic Learning and Social Evolution (2002) “Activities 1995-2002:

A report for the ESRC" London pp.59.

See: http://else.econ.ucl.ac.uk/newweb/downloads/report1995_2002.pdf 
Charsley, K. (2005) "Unhappy husbands: masculinity and migration in transnational Pakistani marriages" Journal of the Royal Anthropological Institute. 11: 85-105

Coast, E. (2003). "An evaluation of demographers' use of ethnographies." Population Studies 57(3): 337-346.

Das Gupta, M (1987) "Selective discrimination against female children in rural Punjab, India" Population and Development Review 13(1):77-100

Descola, P. (2005). "On anthropological knowledge." Social Anthropology 13(1): 6573.

Finkenthal, M. (2001) Interdisciplinarity: Toward the definition of a metadiscipline? Peter Lang Publishing

Foster, C. 2000. "The limits to low fertility: A biosocial approach," Population and Development Review 26(2): 209-234

Frank, R. (2001). "The misuse of biology in demographic research on racial/ ethnic differences: a reply to van den Oord and Rowe." Demography 38(4): 563-567.

Frickel, (2004) "Building an Interdiscipline: Collective Action Framing and the Rise of Genetic Toxicology" Social Problems. 51(2):269-287

Fry, G. L. A. (2001). "Multifunctional landscapes - towards transdisciplinary research." Landscape and urban planning 57: 159-168.

Gannon, F. (2005) “Multidisciplinarity: by fiat or need?" EMBO reports 6, 12, 1105

Georgiadis, K. (2007) "Understanding low fertility in Athens and London: a comparative ethnographic study" Unpublished $\mathrm{PhD}$ thesis, University of London.

Gerson K. (1985). Hard Choices: How Women Decide between Work, Career and Motherhood. University of California Press.

Greene, M. E. and A. E. Biddlecom (2000). "Absent and problematic men: demographic accounts of male reproductive roles." Population and Development Review 26(1): 81-115.

Greenhalgh, S. (1990) "Toward a political economy of fertility: Anthropological contributions," Population and Development Review 16: 85-106

Greenhalgh, S. (1995). Anthropology Theorizes Reproduction: Integrating Practice, Political Economic, and Feminist Perspectives. In Situating Fertility. 
Anthropological and Demographic Inquiry. S. Greenhalgh. Cambridge, Cambridge University Press: 3-28.

Greenhalgh 1997) "Methods and Meanings: Reflections on Disciplinary Difference" Population and development Review 23(4):819-824

Greenhalgh, S. (2001). "Review of "re-drawing boundaries: work, households, and gender in China" by B. Entwistle \& G. E. Henderson." Population and Development Review 27(3): 611.

Gregor, T. A. \& D. Tuzin (2001) (eds) Gender in Amazonia and Melanesia: an exploration of the comparative method University of California Press: Berkeley, CA.

Haberli, R. and e. al (2001). Synthesis. Transdisciplinarity: joint problem solving among science, technology and society. J. T. Klein and J. T. Klein. Basel, Birkhauser Verlag: 67-80.

Hampshire, K. R., E. Hills \& N. Iqbal (2005) "Power Relations in Participatory Research and Community Development: a Case Study from Northern England" Human Organization 64(4):340-349

Hammel, E. A. (1990) "A theory of culture for demography" Population and Development Review 16(3) 455-485

Hardin, G. (1991) "From shortage to longage: Forty years in the population vineyards" Population and environment 12(3):339

Harriss, J. (2002). "The case for cross-disciplinary approaches in international development." World Development 30(3): 487-496.

Heberlein, T. A. (1988). "Improving interdisciplinary research: integrating the social and natural sciences." Soc Natur Resources 1: 5-16.

Heintz, C. and G. Origgi (2003). Rethinking interdisciplinarity: emergent issues, Interdisciplines.

Jackson, C. (2002). "Disciplining gender?" World Development 30(3): 497-509.

Johnson-Hanks, J. "Review of Demography in the age of the postmodern by N. E. Riley \& J. McCarthy." Population and Development Review 29(4): 733-736.

Jordan, B. (1992). Birth in Four Cultures : A Crosscultural Investigation of Childbirth in Yucatan, Holland, Sweden, and the United States, Waveland Press.

Keenan, J. (2006). Handbook of Nomads. D. Chatty, Brill. 
Kertzer, D. I. and T. Fricke, Eds. (1997). Anthropological demography: toward a new synthesis. Chicago, University of Chicago Press.

Keyfitz, N. (1993) "Thirty years of demography and Demography" Demography 30(4):533-549

Klein, J. T. (1990). Interdisciplinarity: history, theory and practice. Detroit, MI, Wayne State University Press.

Klein, J. T. (1996). Crossing Boundaries: Knowledge, Disciplinarities, and Interdisciplinarities. University Press of Virginia

Klein, J. T. and W. H. Newell (1998). Advancing interdisciplinary studies. Interdisciplinarity: essays from the literature. W. H. Newell. New York, College Entrance Examination Board: 3-22.

Kockelmans, J. J. 1979 "Why interdisciplinarity? In J. J. Kockelmans (Ed.), Interdisciplinarity and higher education (pp. 123-160). University Park: Pennsylvania State University

Lattuca, L. R. (2001). Creating interdisciplinarity: Interdisciplinary research and teaching among college and university faculty. Nashville, T.N., Vanderbilt University Press.

Lattuca, L. R. (2002). "Learning interdisciplinarity: sociocultural perspectives on academic work." The Journal of Higher Education 73(6): 711-739.

Lattuca, L. R., L. J. Voigt \& K.Q. Fath (2004). "Does interdisciplinarity promote learning? Theoretical support and researchable questions." The Review of Higher Education 28(1): 23-48.

Lesthaeghe, R. (1998). "On theory development: applications to the study of family formation." Population and Development Review 24(1): 1-14.

Liu, Z. \& C. Wang (2005) "Mapping interdisciplinarity in demography: a journal network analysis" Journal of Information Science, Vol. 31, No. 4, 308-316

McKinnon, A. (1997). Love and Freedom: professional women and the reshaping of personal life. Cambridge, Cambridge University Press.

Mansilla, V. B., D. Dillon \& K. Middlebrooks (2000). Building bridges across disciplines: organizational and individual qualities of exemplary interdisciplinary work. Interdisciplinary studies project. Cambridge, MA., Project Zero, Harvard Graduate School of Education. 
Mansilla, V. B. \& H. Gardner (2003) "Assessing interdisciplinary work at the frontier: an empirical exploration of "symptoms of quality" Paper presented at Rethinking Interdisciplinarity, an online seminar. 1/ 12/ 2003. See: http://www.pzweb.harvard.edu/interdisciplinary/pdf/AssessingSymptoms.pdf

Marzano, M., D. N. Carss, S. Bell (2006) "Working to Make Interdisciplinarity Work: Investing in Communication and Interpersonal Relationships" Journal of Agricultural Economics 57(2):185-197

McGregor, J. A. (2004). Researching well-being: communicating between the needs of policy makers and the needs of people. International Workshop on Researching Well-being in Developing Countries, Delmenhorst, Germany.

Metzger, N. and N. Zare (1999). "Interdisciplinary research: from belief to reality." Science 283: 642.

Miller, M. and V. B. Mansilla (2004). Thinking across perspectives and disciplines. Cambridge, MA, Interdisciplinary studies project: Project Zero, Harvard Graduate School of Education.

Mosley, W. H. \& Chen 1984 "An analytical framework for the study of child survival in developing countries: child survival: strategies for research" Population and Development Review 10 (Suppl), 25-45

Muhuri, P. K. \& S. H. Preston 1991) "Effects of Family Composition on Mortality Differentials by Sex Among Children in Matlab, Bangladesh" Population and Development Review 17(3) 415-

Nowotny, H. (2003). The potential of transdisciplinarity. Rethinking interdisciplinarity, Interdisciplines.

POPIN (1993). POPIN Thesaurus: Population multilingual thesaurus. $3^{\text {rd }}$ Edition. English Version. United Nations. New York. pp.276

Population and Development Review 23(4): 813-818.

Paxton, J. D. (1996). "Modes of interaction between disciplines." The Journal of Education 45(2): 79-96.

Pebley, A. (1998). "Demography and the environment." Demography 35(4): 377-389.

Presser, H. B. (1997). "Demography, feminism, and the science-policy nexus." Population and Development Review 23(2): 295-331.

Procter, I., \& Padfield, M. (1998). The effect of the interview on the interviewee. International Journal of Social Research Methodology, 1(2), 123-136 
Randall, S. C. and T. Koppenhaver (2004). "Qualitative data in Demography: the sound of silence and other problems." Demographic Research 11(3): 57-96.

Randall, S. C. 2006 Paper presented at "Changing paradigms in demography: searching for mixed methodologies" Institute Superieur des Sciences de la Population, Ouagadougou, Burking Faso

Rapport, N. (2000). "Review of "Anthropological theory today" by H. Moore (Ed.)." The Journal of the Royal Anthropological Institute 6(4): 736-737.

Riley, N. E. \& J. McCarthy 2003 Demography in the age of the postmodern Cambridge University Press

Rindfuss, R. R., S. P. Morgan \& G. Swicegood (1988) First births in America University of California Press, Berkeley, CA

Rogers, Y., M. Scaife \& A. Rizzo (2005) Interdisciplinarity: an emergent or engineered process? Cognitive Science research Paper No. 556, University of Sussex

Roth, E. A. (2004) Culture, biology and anthropological demography. Cambridge University Press

Ryan, G. \& H. R. Bernard (2000) Data management and analysis methods. In N. Denzin \& Y. Lincoln Handbook of qualitative research $2^{\text {nd }}$ Edition. Pp.769-802

Schoenberger, E. (2001). "Interdisciplinarity and social power." Progress in human geography 25(3): 365-382.

Shaw, A. (2000). Kinship and continuity: Pakistani families in Britain. Amsterdam, Harwood Academic.

Sperber, D. (2003). Why rethink interdisciplinarity? Virtual seminar on "Rethinking Interdisciplinarity", Interdisciplines.

Stember, M. (1991). Advancing the social sciences through the interdisciplinary enterprise. The Social Science Journal, 28, 1-14.

Stenning D. (1995 [1959]) Savannah Nomads. London: James Currey

Strathern, M. (2005). "Experiments in interdisciplinarity." Social Anthropology 13(1): 75-90.

Stycos, J. M. (1987) “Demography as an interdiscipline', Sociological Forum, 2 (4)

The Global Science Panel on Population in Sustainable Development (2002). "The global science panel on population in sustainable development." Population and Development Review 28(2): 367-369. 
Vetta, A. and D. Courgeau (2003). "Demographic Behaviour and Behaviour Genetics." Population 58(4/5): 401-428.

Weingart, P. and N. Stehr (1999). Practising interdisciplinarity. Toronto, University of Toronto Press.

Werbner, P. (2002). Imagined diasporas among Manchester Muslims : the public performance of Pakistani transnational identity politics. Oxford, James Currey. 
Coast, Hampshire \& Randall: Disciplining anthropological demography 